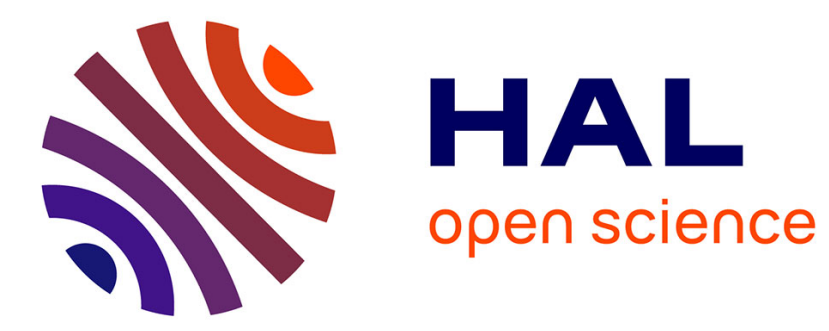

\title{
Investigation of initial stage of chemical etching of ion tracks in polycarbonate
}

\author{
N. Sertova, E. Balanzat, M. Toulemonde, C. Trautmann
}

\section{To cite this version:}

N. Sertova, E. Balanzat, M. Toulemonde, C. Trautmann. Investigation of initial stage of chemical etching of ion tracks in polycarbonate. The Seventh International Symposium on Swift Heavy Ions in Matter, Jun 2008, Lyon, France. hal-00219753

\section{HAL Id: hal-00219753 https://hal.science/hal-00219753}

Submitted on 30 Jun 2008

HAL is a multi-disciplinary open access archive for the deposit and dissemination of scientific research documents, whether they are published or not. The documents may come from teaching and research institutions in France or abroad, or from public or private research centers.
L'archive ouverte pluridisciplinaire HAL, est destinée au dépôt et à la diffusion de documents scientifiques de niveau recherche, publiés ou non, émanant des établissements d'enseignement et de recherche français ou étrangers, des laboratoires publics ou privés. 
Investigation of initial stage of chemical etching of ion tracks in polycarbonate

\author{
N. Sertova ${ }^{1}$, E. Balanzat ${ }^{1}$, M. Toulemonde ${ }^{1}$, C. Trautmann ${ }^{2}$ \\ ${ }^{1}$ CIMAP, laboratoire CEA-CNRS-ENSICAEN-Université de Caen, BP 5133, 14070 Caen-Cedex 5, France \\ ${ }^{2}$ Materialforschung, GSI, Planckstr. 1, 64291 Darmstadt, Germany
}

\begin{abstract}
Chemical track etching and the growth of nanochannels in ion-irradiated polycarbonate foils were investigated by loss of weight measurements and IR-spectroscopy. The data provided by both methods are in good agreement and allow us to shed light on the early stage of pore formation including times where the breakthrough of the pores has not yet occurred. Clear evidence is shown that the pore growth as a function of etching time depends on the irradiation fluence. For fixed etching parameters, foils containing $7 \times 10^{9}$ tracks $/ \mathrm{cm}^{2}$ exhibit much smaller pores than samples with $2 \times 10^{8}$ tracks $/ \mathrm{cm}^{2}$. This effect is independent of the etching temperature and appears for irradiations with $\mathrm{Pb}$ ions as well as for $\mathrm{Ca}$-ion tracks sensitized by UV exposure. Model calculations for different etching times and fluences show that the data for low track densities can be fitted quite well by describing the radial etching rate by the track etch rate changing into the bulk etch rate with a Gaussian-shaped transition.
\end{abstract}

Keywords: polycarbonate, ion tracks, chemical etching, fluence, weight loss, infrared spectroscopy 


\section{Introduction}

When exposing polymer foils to swift heavy ions of energy in the $\mathrm{MeV}$ to $\mathrm{GeV}$ range, each projectile produces a cylindrical track of physically or chemically modified material. The diameter of these tracks is typically a few nanometers, whereas their length is of the order of several tens of micrometers depending on the initial kinetic energy of the projectiles [1-3]. The polymer damaged along the ion trajectory exhibits a higher chemical reactivity as compared to the surrounding matrix material and is therefore more susceptible to chemical attack. With a suitable etchant, tracks can be transformed into long cylindrical pores with diameters between several tens of nanometers up to a few micrometers. In the past, etched tracks have been studied by various techniques such as scanning and transmission electron microscopy [4-6], scanning force microscopy [7-10], electrical conductivity measurements [11-13], small-angle x-ray scattering [14-16], and galvanic replication [17-23]. The porosity of track-etch membranes can be adjusted by the pore density (irradiation fluence) and the pore size primarily tuned by the parameters of the etching process (e.g. etching time, concentration and temperature of the etchant). Such membranes have many different scientific and industrial applications; most recent studies focus on extremely small single pores suitable as bio-sensors [24] or to mimic ion channels in biological cell membranes $[20,25,26]$. There exists also significant effort to increase the integral porosity of nanoporous membranes by using larger irradiation fluences and shorter etching times.

In the present work, we investigate the track-etching behavior of polycarbonate foils exposed to different irradiation fluences. The initial stage of the pore growth during track etching is analyzed by measuring the loss of matter either by recording the weight loss and/or by monitoring the intensity decrease of specific absorption bands by infrared (IR) spectroscopy. For 
some of the samples, the pore size on the membrane surface was measured by scanning electron microscopy. Model calculations, fitting the radial etching rate to the weight loss data, help to better understand the etching process and allow predictions of the pore size evolution even before the moment of pore break through.

\section{Experimental}

\subsection{Material and ion irradiation}

As samples we used amorphous polycarbonate foils from different providers: $\sim 30 \mu \mathrm{m}$ thick Makrofol KG (Bayer, Germany) and $20 \mu \mathrm{m}$ thick Pokalon (LOFO, Germany). The nominal mass density is $\rho=1.2 \mathrm{~g} / \mathrm{cm}^{3}$ and the monomer repeat unit is $\mathrm{H}_{14} \mathrm{C}_{16} \mathrm{O}_{3}$. Prior to irradiation, all samples were preetched to $18 \pm 2 \mu \mathrm{m}$ in order to remove the surface layer which may exhibit a different etching behavior than the bulk polymer.

The irradiation experiments were performed at the GANIL accelerator (Caen, France) under normal beam incidence. The Makrofol samples were exposed to ${ }^{48} \mathrm{Ca}$ ions of $9.3 \mathrm{MeV} / \mathrm{u}$ of fluence $5 \times 10^{8}$ ions $/ \mathrm{cm}^{2}$, whereas Pokalon was irradiated with ${ }^{208} \mathrm{~Pb}$ ions of $29 \mathrm{MeV} / \mathrm{u}$ applying fluences between $2 \times 10^{8}$ and $7 \times 10^{9}$ ions $/ \mathrm{cm}^{2}$ with an accuracy of about $\pm 10 \%$. The flux was $2.5 \times 10^{6} \mathrm{~Pb} / \mathrm{cm}^{2} \mathrm{~s}$ and $5 \times 10^{6} \mathrm{Ca} / \mathrm{cm}^{2} \mathrm{~s}$ and was monitored with a secondary-electron emitting Alfoil detector [27] calibrated with a Faraday cup. Using the parasitic beam of another experiment, we could not freely select the most suitable beam energy. Therefore, thin Al foils were placed in front of the samples degrading the initial ion energy to about $4 \mathrm{MeV} / \mathrm{u}$ for the $\mathrm{Ca}$ ions $(\mathrm{dE} / \mathrm{dx}=$ 2.6 $\mathrm{keV} / \mathrm{nm}$ or $23 \mathrm{MeV} \mathrm{cm}^{2} \mathrm{mg}^{-1}$ ) and to 5.3 and $4.5 \mathrm{MeV} / \mathrm{u}(\mathrm{dE} / \mathrm{dx} \sim 15.3 \mathrm{keV} / \mathrm{nm}$ or $\sim 128 \mathrm{MeV}$ $\mathrm{cm}^{2} \mathrm{mg}^{-1}$ ) for the $\mathrm{Pb}$ ions [28]. The sample area exposed to the scanned beam was $5 \times 5 \mathrm{~cm}^{2}$. 
After irradiation, the central part $\left(4 \times 4 \mathrm{~cm}^{2}\right)$ of each foil was divided into 16 pieces of $1 \times 1$ $\mathrm{cm}^{2}$ and stored in the dark at ambient conditions. Before etching, both sides of samples irradiated with $\mathrm{Ca}$ ions were exposed (30 $\mathrm{min}$ ) to UV light (wavelength range 310-360 $\mathrm{nm}$ ). This treatment is known to accelerates natural track aging resulting in an increase of the track-etch rate in particular for light ions $[6,16]$. Most samples were etched within 1-3 months after irradiation, a few additional cross-check tests were carried out about 2 years later.

\subsection{Chemical etching and analysis of material loss}

Chemical etching was performed in aqueous solution of $5 \mathrm{~N} \mathrm{NaOH}$ utilizing a separate beaker $\left(\sim 250 \mathrm{~cm}^{3}\right)$ for each sample. The etchant was agitated by a magnet stirrer and had a temperature of either $\mathrm{T}=40 \pm 1{ }^{\circ} \mathrm{C}$ or $\mathrm{T}=60 \pm 1^{\circ} \mathrm{C}$. A new sample was used for each parameter set given by the ion species, fluence, temperature, etching time, and UV treatment. After etching, the films were rinsed in distilled water and furnace-dried at $120^{\circ} \mathrm{C}$ in order to evaporate residual water from the pore channels.

Each sample irradiated with fluence $\Phi$ was weighed before $\left(\mathrm{W}_{0}\right)$ and after chemical etching of duration $\mathrm{t}\left(\mathrm{W}_{\Phi}(\mathrm{t})\right)$. The weight loss $\Delta \mathrm{W}_{\Phi}(\mathrm{t})$ is given by

$$
\Delta \mathrm{W}_{\Phi}(\mathrm{t})=\left(\mathrm{W}_{0}-\mathrm{W}_{\Phi}(\mathrm{t})\right)
$$

The mean weight loss was deduced from 8 independent measurements using the tara method. Before each measurement the instrumental accuracy and stability of the scale was $1 \times 10^{-5} \mathrm{~g}$ as given by the manufacturer and cross checked with a test sample.

In parallel, each irradiated sample was inspected by infrared spectroscopy (Thermo Nicolet Nexus) in transmission geometry. For both polymers, the $1365 \mathrm{~cm}^{-1}$ absorption band (symmetrical C-H deformation vibration of the isopropyl group) was analyzed. In addition, the 
$2970 \mathrm{~cm}^{-1}$ band (C-H stretching vibration of the isopropyl group) of Makrofol and the $830 \mathrm{~cm}^{-1}$ band (out of plane $\mathrm{C}-\mathrm{H}$ vibrations of the aromatic ring) of Pokalon was evaluated. For both bands the background was sufficiently small for quantitative analysis. The area of the selected bands was quantified by a peak-fitting procedure after background subtraction. For each fluence the relative reduction of a specific band area $\Delta \mathrm{I}_{\Phi}(\mathrm{t})$ versus the etching time $\mathrm{t}$ was determined according to

$$
\Delta \mathrm{I}_{\Phi}(\mathrm{t})=\left(\mathrm{I}_{0}-\mathrm{I}_{\Phi}(\mathrm{t})\right) / \mathrm{I}_{0}
$$

where $I_{0}$ and $I_{\Phi}(t)$ denotes the band area respectively before and after the etching process. To ensure that both types of polycarbonates are amorphous, it was verified that the IR absorption did not depend on the foil orientation. The data reproducibility for different samples of a given parameter combination (fluence, etching time, and UV treatment) was in average better than $80 \%$.

The bulk etch rate $\left(\mathrm{V}_{\mathrm{b}}\right)$ of non-irradiated polycarbonate foils was determined by measuring the loss of weight and the decrease of the foil thickness $\Delta \mathrm{d}$ as a function of etch time. For Makrofol as well as for Pokalon, a mean bulk etch rate of $\mathrm{V}_{\mathrm{b}}\left(\mathrm{T}=60^{\circ} \mathrm{C}\right)=6.2 \pm 1.0 \mathrm{~nm} / \mathrm{min}$ and $\mathrm{V}_{\mathrm{b}}\left(\mathrm{T}=40^{\circ} \mathrm{C}\right)=1.4 \pm 0.3 \mathrm{~nm} / \mathrm{min}$ was deduced, in fair agreement with values reported earlier $[5,29,30]$.

After etching, some of the samples were sputter-coated with a thin layer of gold and inspected by scanning electron microscopy (Philips XS30).

\section{Results}

To compare the weight measurements and the results from IR spectroscopy, we converted the relative intensity loss $\Delta \mathrm{I}_{\Phi}(\mathrm{t})$ of the IR band into a loss of mass $\Delta \mathrm{W}_{\mathrm{IR}, \Phi}(\mathrm{t})$ by 


$$
\Delta \mathrm{W}_{\mathrm{IR}, \Phi}(\mathrm{t})=\Delta \mathrm{I}_{\Phi}(\mathrm{t}) \times \mathrm{W}_{0}
$$

Figure 1 combines the mass loss results deduced from IR spectroscopy as well as from weighing for Makrofol and Pokalon samples exposed to different irradiation and etching parameters. The data show roughly the same evolution with increasing etching time, no matter which type of polycarbonate, fluence, etching temperature, and infrared bands were investigated. Further analysis and discussions are therefore based on values $\left(<\Delta \mathrm{W}_{\Phi}(\mathrm{t})>\right)$ averaged from IR data and direct weight measurements. The graph for Makrofol (Fig. 1a) also includes weighing results obtained two years after the ion irradiation indicating that there is no significant change. The mass loss for low fluence irradiations (Fig. 1a) increases linearly with etching time, whereas the results from high-fluence exposures (Fig. $1 \mathrm{~b}$ and c) seem to be better described by a square law.

\section{Data analysis.}

The expected mass loss $\Delta \mathrm{w}$ of an individual cylindrical pore [11] is deduced by dividing the mean mass $<\Delta \mathrm{W}_{\Phi}(\mathrm{t})>$ by the fluence and then $\mathrm{R}$ is given by the following relation

$$
\Delta \mathrm{w}=\pi \times \mathrm{R}^{2} \times \mathrm{L} \times \rho,
$$

where $\mathrm{L}$ is the thickness of the sample $(18 \pm 2 \mu \mathrm{m})$ and $\rho$ is the mass density of polycarbonate. Pore overlapping effects were considered by the Poisson law [3] but they contribute less than $10 \%$ for the largest radius at highest fluence.

Figures $2 \mathrm{a}$ and $\mathrm{b}$ present $\Delta \mathrm{w}$ versus etching time for different irradiation and etching conditions. The influence of the etching temperature is clearly visible (Fig. 2a), and there is a pronounced effect of the ion fluence (Fig.2b). Instead of being constant, the mass loss per pore decreases systematically the higher the track density is in a given sample. The pore radii deduced 
for different etching times are shown in Figs. 3. Within the experimental errors, the values agree rather well with the pore opening observed at the sample surface by SEM (cf. Fig. 4). There is also consistency with the radius of a Ca-irradiated sample deduced from bulk analysis by means of small-angle x-ray scattering (SAXS) [15] (Fig.3a). The overall agreement confirms that mass loss measurements are appropriate to deduce pore radii.

In order to obtain more detailed information on the pore growth rate, the radial etch velocity $\mathrm{V}_{\mathrm{r}}$ was determined from $\Delta \mathrm{R} / \Delta \mathrm{t}$ from the experimental data points shown in Fig. 3 a and b. When plotting $V_{r}$ as a function of the mean pore radius (Fig. $5 \mathrm{a}$ and $\mathrm{b}$ ), significant differences become apparent; $\mathrm{V}_{\mathrm{r}}$ obviously depends on the pore size and fluence applied. In the initial stage of pore growth, it is reasonable to expect that $V_{r}$ is large due to the quick dissolution of the highly damaged track core $[4,5]$. Beyond this, $V_{r}$ should evolve towards the general bulk etch rate of the

undamaged matrix material. For samples exposed to fluence larger than $1 \times 10^{9}$ ions $/ \mathrm{cm}^{2}, \mathrm{~V}_{\mathrm{r}}$ scatters around $\mathrm{V}_{\mathrm{b}}$ at pore radii as small as about $5 \mathrm{~nm}$ (Fig. $5 \mathrm{a}$ and b), approximately equal to the radius of the highly damaged track core [4,5] whereas at low fluence of $2 \times 10^{8}$ and $5 \times 10^{8}$ ions $/ \mathrm{cm}^{2}$, a smooth transition on several tens of nanometer is observed as previously reported for polycarbonate [36].

\section{Model calculations of the mass loss}

In order to better understand how neighboring tracks influence the $V_{r}$ characteristic near the track core, model calculations were performed. The track etching process is usually described by a simultaneous action of the etchant along the ion track $V_{t}$ and the smaller bulk etch rate $V_{b}$ attacking the surface and the inner pore wall $[2,3]$. According to this simplified approach, the loss of mass per pore should follow a quadratic evolution with increasing etching time as observed for 
our samples exposed to fluences above $10^{9}$ ions $/ \mathrm{cm}^{2}$ (Fig. 1, b and c), and in contrast to the linear increase of the low-fluence samples (Fig. 1a). The discrepancy is probably related to the false assumption that the radial etch velocity changes abruptly from $V_{t}$ to $V_{b}$ at a track radius equal to the track core $[4,5]$

In the present model calculation, $\mathrm{V}_{\mathrm{r}}$ is described by a Gaussian profile of width $\sigma$ and the following boundary conditions: $V_{r}(r=0)=V_{t}$ at the center of the ion track and $V_{r}(r=\infty)=V_{b}$ at large radial distances. For the etch velocities the following expression was used

$$
\mathrm{V}_{\mathrm{r}}(\mathrm{r})=\left(\mathrm{V}_{\mathrm{t}}-\mathrm{V}_{\mathrm{b}}\right) \exp \left(-\mathrm{r}^{2} /\left(2 \sigma^{2}\right)\right)+\mathrm{V}_{\mathrm{b}} \quad \text { and } \quad \mathrm{V}_{\mathrm{t}}=\mathrm{x} / \mathrm{t}
$$

where $x$ denotes the depth of the etch front in the foil. From the increase of $d r\left(d r=V_{r}(r) \times d t\right)$, the corresponding pore volume increase and thus the incremental mass loss $\operatorname{dw}(\mathrm{x}, \mathrm{r})=\rho \mathrm{dx} 2 \pi \mathrm{r} d \mathrm{r}$ is deduced. The calculated data are adjusted to the experimental results using $\sigma$ and $\mathrm{V}_{\mathrm{t}}$ as fit parameter, but excluding $\sigma$ values smaller than the track core $[4,5](\sigma(\mathrm{Ca}) \geq$ $3 \mathrm{~nm}$ and $\sigma(\mathrm{Pb}) \geq 5 \mathrm{~nm})$.

In the case of Pokalon irradiated with $2 \times 10^{9} \mathrm{~Pb} / \mathrm{cm}^{2}$ and etched at either $60^{\circ} \mathrm{C}$ or $40^{\circ} \mathrm{C}$, the quadratic evolution of the mass loss versus etching time can be nicely fitted using $\sigma=5 \mathrm{~nm}$ and respectively $\mathrm{V}_{\mathrm{t}}\left(60^{\circ} \mathrm{C}\right)=2250 \mathrm{~nm} / \mathrm{min}\left(\right.$ Fig. 6 a, solid line) and $\mathrm{V}_{\mathrm{t}}\left(40^{\circ} \mathrm{C}\right)=500 \mathrm{~nm} / \mathrm{min}($ Fig. $6 \mathrm{a}$, dashed line). Such fit values are in agreement with experimental etching rates reported earlier $[31,32]$. According to these $V_{t}$ values, the break through time is 4 and 18 min respectively, indicating that mass loss measurement provides information on the early stage of pore formation.

If $\mathrm{V}_{\mathrm{t}}\left(40^{\circ}\right)=500 \mathrm{~nm} / \mathrm{min}$ deduced from the fit to the high-fluence data is inserted for samples exposed to $2 \times 10^{8} \mathrm{~Pb} / \mathrm{cm}^{2}$, best agreement is obtained for a fit value of $\sigma=9 \mathrm{~nm}$ (Fig. 5 $\mathrm{b}$, dashed line). Obviously the transition range for $\mathrm{V}_{\mathrm{r}}$ is larger (according to Fig. $6 \mathrm{~b}, \mathrm{~V}_{\mathrm{r}}$ reaches $\mathrm{V}_{\mathrm{b}}$ at a pore radius of about $30 \mathrm{~nm}$ ). Applying the same fit parameters to the weight loss data of 
the high-fluence irradiations $\left(7 \times 10^{9} \mathrm{~Pb} / \mathrm{cm}^{2}\right)$ etched at $40^{\circ} \mathrm{C}$, it is not possible to describe the small weight loss observed experimentally, unless the track etch rate is decreased to $V_{t}=150$ $\mathrm{nm} / \mathrm{min}$ (Fig. $6 \mathrm{~b}$, dotted line). At the present stage, it is not clear if such a small $\mathrm{V}_{\mathrm{t}}$ value has a physical meaning, because also a more complex radial dependence of $\mathrm{V}_{\mathrm{r}}$ could describe the curve. At a certain radius $V_{r}$ could e.g. become smaller than $V_{b}$ (cf. Fig. $5 b$ ) as experimentally also observed by Apel et al. $[12,37,38]$. Based on the data presented here, it is not possible to clarify the situation without having more information about the true value of the track etch rate at high fluences.

For the Makrofol samples irradiated with $\mathrm{Ca} / \mathrm{cm}^{2}$ and etched at $60^{\circ} \mathrm{C}$ after UV exposure, numerous combinations of $\sigma(24-10 \mathrm{~nm})$ and $\mathrm{V}_{\mathrm{t}}(1550-10000 \mathrm{~nm} / \mathrm{min})$ have been tested as fit parameters. Best agreement was obtained for $\sigma=15 \mathrm{~nm}$ and $\mathrm{V}_{\mathrm{t}} \sim 3900 \mathrm{~nm} / \mathrm{min}$ consistent with experimental results under similar track etching conditions [11]. It is not possible to fit $\mathrm{V}_{\mathrm{t}}$ to the mass loss data with $\sigma=3 \mathrm{~nm}$, corresponding to the track core. Compared to the fit parameters deduced for the irradiation with $\mathrm{Pb}$ ions, the large $\mathrm{V}_{\mathrm{t}}$ value for $\mathrm{Ca}$ tracks is possibly due to the UV treatment that may strongly modifies the track core parameters.

\section{Discussion and conclusions}

Track etching and the growth of nanochannels in ion-irradiated polycarbonate foils were investigated by loss of weight measurements complemented by IR-spectroscopy. The data provided by both methods are in good agreement and allow us to shed light into the early stage of pore formation, even at times where the breakthrough of the pores has not yet occurred. We found clear evidence that the pore growth as a function of etching time depends on the irradiation

fluence. For fixed etching parameters, foils containing $7 \times 10^{9}$ tracks $/ \mathrm{cm}^{2}$ exhibit much smaller 
pores than samples with $2 \times 10^{8}$ tracks $/ \mathrm{cm}^{2}$. This effect appears for $\mathrm{Pb}$ as well as for $\mathrm{Ca}$ ions tracks and is independent of the etching temperature and UV treatment,.

At ion fluences equal or below $5 \times 10^{8}$ ions $/ \mathrm{cm}^{2}$, the tracks can be considered as individual objects, and the radial etching velocity smoothly evolves from the track to the bulk etching rate as expected. For the 4-5 MeV/u beam energy used here, $V_{r}$ is larger than $V_{b}$ up to a distance of several tens of $\mathrm{nm}$ from the track axis. Details of the radial evolution of $\mathrm{V}_{\mathrm{r}}$ seem to be influenced by the temperature of the etchant and probably also by the ion species and/or UV treatment.

At higher fluences, the radial etching rate does not exhibit this $\mathrm{V}_{\mathrm{t}}$-to- $\mathrm{V}_{\mathrm{b}}$ transition, but scatters around or even below $V_{b}$. This observation is surprising because high fluence samples should contain overlapping track zones consisting of higher damage. The radial etch rate therefore should be increased instead of decreased.

Model calculations for different etching times and fluences show that the data for low track densities can be fitted quite well by describing the radial etching rate with a Gaussian-shaped transition zone. Best fits yield track etching rates in fair agreement with published data, whereas at track densities above $5 \times 10^{9}$ ions $/ \mathrm{cm}^{2}$, the fit parameters require inconsistent or unrealistic values. For better understanding and additional simulations, the knowledge of the track etch rate would be helpful.

Earlier etching experiments performed on single tracks in other polymers, monitored by conductometric measurements reported evidence of a radial zone of decreased $V_{r}[37,38]$. It was speculated that the reduced etching could be due to cross linking. Contrariwise, radiation damage in polymers induced by swift heavy ions in the electronic stopping regime is in general dominated by scission processes responsible for the large track etching rates. On the other hand, one may speculate that cross linking for a specific type of polymer depends on the deposited 
dose, and overlapping of neighboring tracks may lead to a selected zone in which cross linking is a dominant process. Also compaction of the polymer structure around the track core induced e.g. by shock waves during track formation could be an explanation for the observed effects [39].

In conclusion, it should be emphasized that track overlapping may influence the etching process of polycarbonate membranes. Above $5 \times 10^{8}$ tracks $/ \mathrm{cm}^{2}$, the radial etching rate is slowed down the larger the track densities. To produce highly porous ion-track membranes with reliable pore diameters, the etching parameters cannot be extrapolated from low-fluence samples but have to be carefully readjusted.

\section{Acknowledgments:}

Valuable discussions with T. Cornelius, B. Schiedt, E. Toimil, and S. Ziwy are gratefully acknowledged. Special thanks to B. Schiedt for her help with SEM imaging. One of the author (N. S.) was supported by the European research and training network EuNITT (HPRN-CT-200000047).

\section{References}

[1] P.B. Price and R.M. Walker, J. Appl. Phys. 33 (1962) 3407

[2] R.L. Fleischer, P.B. Price, R.M. Walker, in : Nuclear Tracks in Solids (Univ. of California Press, 1975).

[3] R. Spohr, in: Ion Tracks and Microtechnology. Basic Principles and Applications, ed. K. Bethge, Vieweg, Braunschweig (1990)

[4] A. Adla, H. Fuess, C. Trautmann, J. Poly. Sci. 41 (2003) 2892

[5] S.A. Saleh, Y. Eyal, Nucl. Instr. Meth. B 208 (2003) 137 
[6] E. Ferain, R. Legras, Nucl. Instr. and Meth. B 174 (2001) 116

[7] J. Ackermann, S. Grafström, M. Neitzert, R. Neumann, C. Trautmann, J. Vetter, N. Angert, Rad. Eff. Def. Sol. 126 (1993) 213

[8] A. Dallanora, T. L. Marcondes, G. G. Bermudez, P. F. P. Fichtner, C. Trautmann, M. Toulemonde, and R. M. Papaléo, J. Appl. Phys. 104 (2008) 024307

[9] F. Ohnesorge, R. Neumann, Europh. Lett. 50 (2000) 742

[10] C. Milanez Silva, P. Varisco, A. Moehlecke, P.P. Fichtner, R.M. Papaléo, J. Eriksson, Nucl. Instr. Meth. B 206 (2003) 486

[11] E. Ferain, R. Legras, Nucl. Instr. Meth. B 84 (1994) 331

[12] P. Apel, A. Schulz, R. Spohr, C. Trautmann, V. Vutsadakis, Nucl. Instr. Meth. B 131 (1997) 55

[13] A. Wolf, N. Reber, P. Apel, B.E. Fischer, R. Spohr, Nucl. Instr. Meth. B 105 (1995) 291

[14] E. Ferain, R. Legras, Nucl. Instr. Meth. B 131 (1997) 97.

[15] G. Pépy, E. Balanzat, B. Jean, A. Kuklin, N. Sertova, M. Toulemonde, J. of Appl. Cryst. 36 (2003) 649

[16] G. Pépy, P. Boesecke, A. Kuklin, E. Manceau, B. Schiedt, Z. Siwy, M. Toulemonde, C. Trautmann, J. of Appl. Cryst. 40 (2007) 388

[17] D. Dobrev, J. Vetter, R. Neumann, N. Angert, J. Vac. Sci. Technol. B 19 (2001) 1385

[18] P. Apel, Nucl. Instr. Meth. B 208 (2003) 11

[19] E. Ferain, R. Legras, Nucl. Instr. Meth. B 208 (2003) 115

[20] Z. Siwy, P. Apel, D. Baur, D. Dobrev, Y.E. Korchev, R. Neumann, R. Spohr, C. Trautmann, K. O. Voss, Surface Science 532 (2003) 1061

[21] A. Fert, L. Piraux, J. Magn. Magn. Mater. 200 (1998) 338 
[22] N. Hermsdorf, M. Stamm, S. Förster, S. Cunis, S.S. Funari, R. Gehrke, P. MüllerBuschbaum, Langmuir 21 (2005) 11987

[23] J.C. Bourdin, R. Mazzei, O.A. Bernaola, J.C. Grasso, G. Saint Martin, Nucl. Instr. Meth. B 28 (1987) 548

[24] A. Mara, Z. Siwy, C. Trautmann, J. Wan, F. Kamme, Nano Letters 4 (2004) 497

[25] C.R Martin, Science 266 (1994) 1961

[26] E.A. Heins, Z.S. Siwy, L.A. Baker, C.R. Martin Nano Letters 5 (2005) 1824

[27] S. Bouffard, J. Dural, F. Lesvesque, J.M. Ramillon, Annales de Physique (Paris) 14 (1989) 395

[28] SRIM-2003, J.F. Ziegler Nucl. Instr. Meth. B 219-220 (2004) 1027

[29] P. Apel, L.I. Kravets, V.I. Kuznetsov, A.Yu. Didyk, High Ener. Chem. 23 (1989) 233 (from Khim. Vyso. Ener. 23 (1987) 327)

[30] U. Heyna, W. Enge, G. Sermund, R. Beaujean, Nucl. Tracks 12 (1986) 33

[31] J. Tripier and M. Debeauvais, Nucl. Instr. Meth. 147 (1977) 221

[32] T.W. Cornelius, P.Yu. Apel, B. Schiedt, C. Trautmann, M.E. Toimil-Molares, S. Karim, R. Neumann, Nucl. Instr. Meth. B 265 (2007) 553

[33] M. Skupinski, M. Toulemonde, M. Lindberg, K. Hjort, Nucl. Instr. Meth. B 240 (2005) 681

[34] D. Albrecht, P. Armbruster, R. Spohr, M. Roth, K. Schaupert, H. Stuhrmann, Appl. Phys. A $37(1985) 37$

[35] S.A. Saleh, Y. Eyal, Appl. Phys. Lett. 85 (2004) 2529

[36] F. Petersen and W. Enge Rad. Meas. 25 (1995) 43

[37] P. Apel, I.V. Blonskaya, V.R. Oganessian, O.L. Orelovitch, C. Trautmann, Nucl. Instr. Meth. B 185 (2001) 216 
[38] P. Apel, A. Schulz, R. Spohr, C. Trautmann, V. Vutsadakis, Nucl. Instr. Meth. B 146 (1998) 468

[39] D.A. Kolesnikov, C.T. Reimann, I.V. Vorobyova, Nucl. Instr. Meth. B 122 (1997) 255 


\section{Figure Captions}

\section{Figure 1:}

Mass loss as a function of etching time of (a) Makrofol foils irradiated with $5 \times 10^{8} \mathrm{Ca}$-ions $/ \mathrm{cm}^{2}$, etched at $60^{\circ} \mathrm{C}$, (b) Pokalon foils with $2 \times 10^{9} \mathrm{~Pb}$ ions $/ \mathrm{cm}^{2}$, etched at $60^{\circ} \mathrm{C}$, (c) Pokalon foils with $2 \times 10^{9} \mathrm{~Pb}$ ions $/ \mathrm{cm}^{2}$, etched at $40^{\circ} \mathrm{C}$. Open symbols denote loss of weight data, full symbols are deduced from IR absorption measurements. The dashed lines represent a linear or quadratic fit to specific data ensemble.

\section{Figure 2:}

Mean mass loss per pore as a function of the etching time (a) for different ions and etching conditions and (b) for different fluences using $\mathrm{Pb}$ ions and etching at $40^{\circ} \mathrm{C}$.

\section{Figure 3 a and $\mathbf{b}$ :}

Mean pore radius as a function of etching time for different ions, fluences, and etching temperatures. The open symbols in (a) show pore radii deduced from the same sample set by using small-angle $\mathrm{x}$-ray scattering. The lines are guides to the eye.

\section{Figure 4:}

SEM images of pores obtained for different irradiation and etching conditions (a) Makrofol irradiated with $5 \times 10^{8} \mathrm{Ca}$-ions $/ \mathrm{cm}^{2}$, UV treated, and etched for 4 min at $\mathrm{T}=60{ }^{\circ} \mathrm{C}$, and (b) Pokalon irradiated with $2 \times 10^{9} \mathrm{~Pb}$-ions $/ \mathrm{cm}^{2}$ and etched for $30 \mathrm{~min}$ at $\mathrm{T}=40^{\circ} \mathrm{C}$. The mean pore radius at the surface is (a) $65 \pm 15 \mathrm{~nm}$ and (b) $35 \pm 10 \mathrm{~nm}$. 
Figure 5: Radial etching rate $\left(V_{r}\right)$ versus the pore radius $(R)$ for different ions and fluences etched at (a) $60^{\circ} \mathrm{C}$ and (b) $40^{\circ} \mathrm{C} . \mathrm{V}_{\mathrm{b}}$ is the bulk etching rate for the corresponding temperatures. The dashed lines are guides to the eye.

Figure 6 a and b: Mean mass loss as a function of etching time for $\mathrm{Pb}$ ions (a) of fixed fluence at different temperature and (b) of fixed etching conditions and different fluences. 

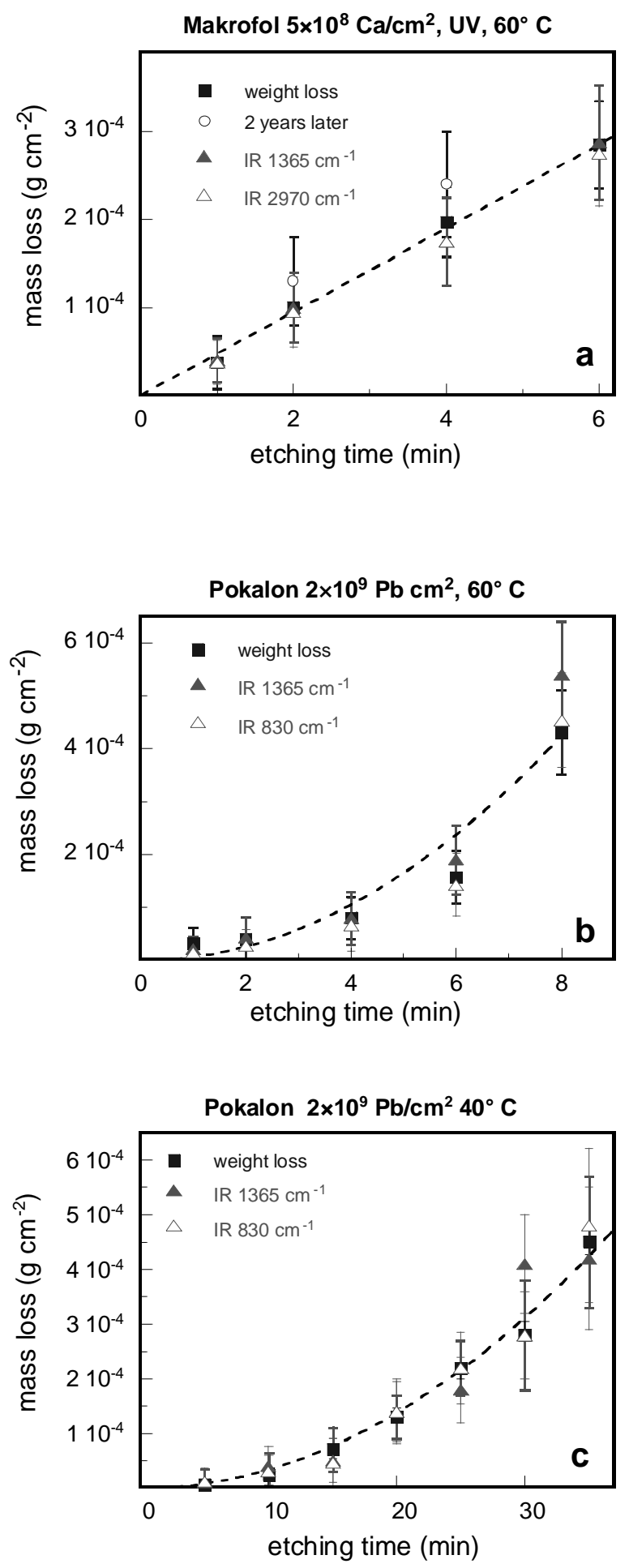

Figure 1a,b,c 

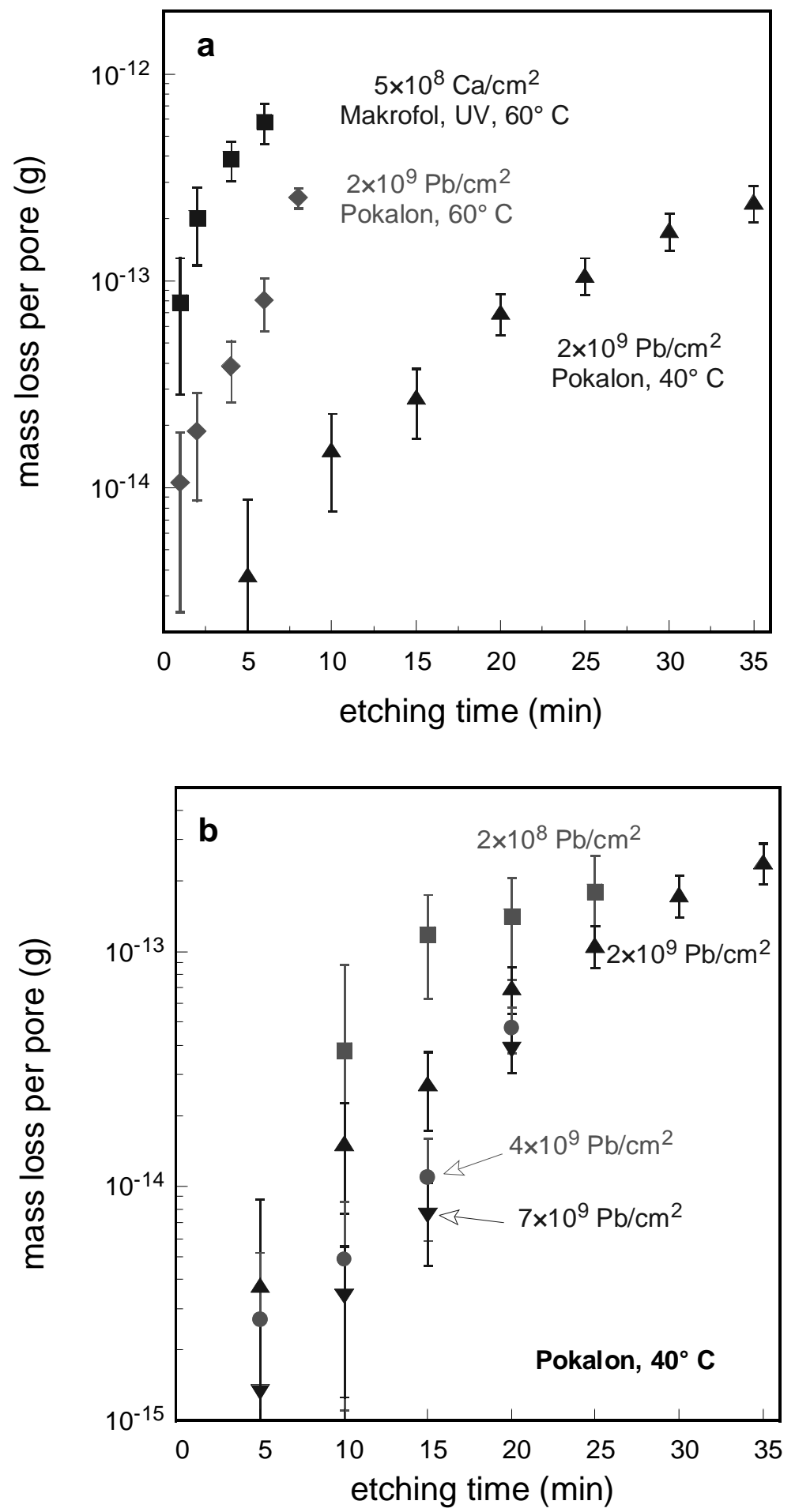

Figure 2a and 2b 

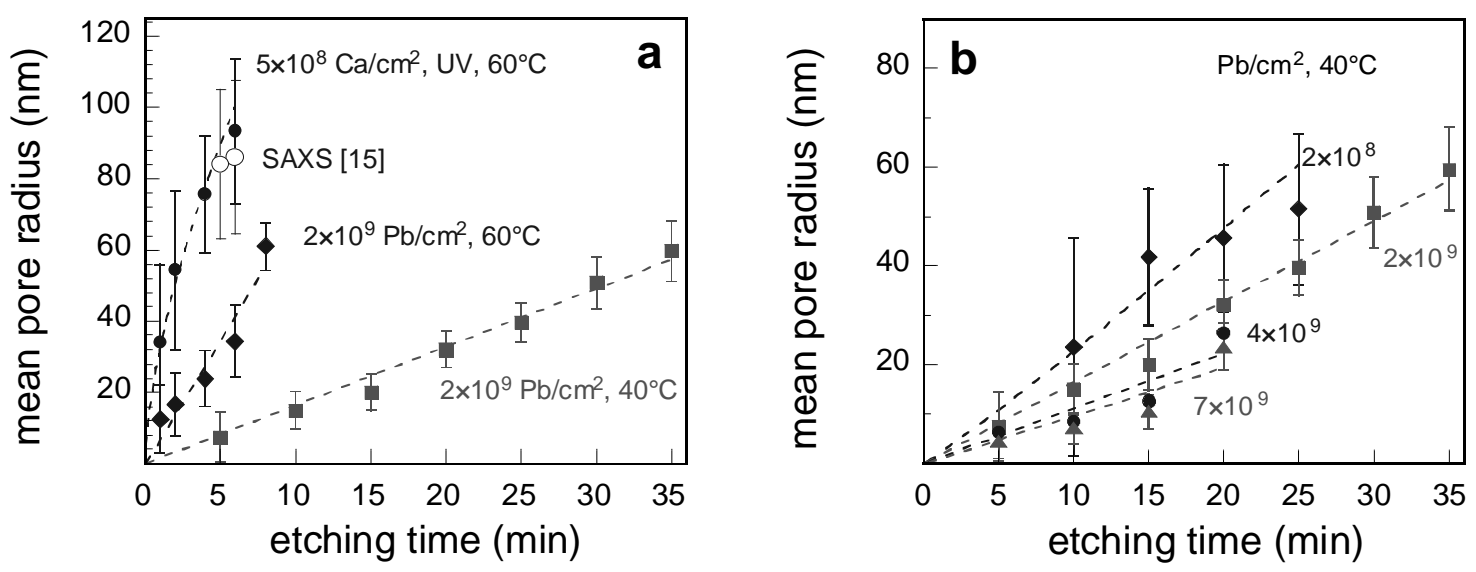

Figure $3 \mathrm{a}$ and $b$ 

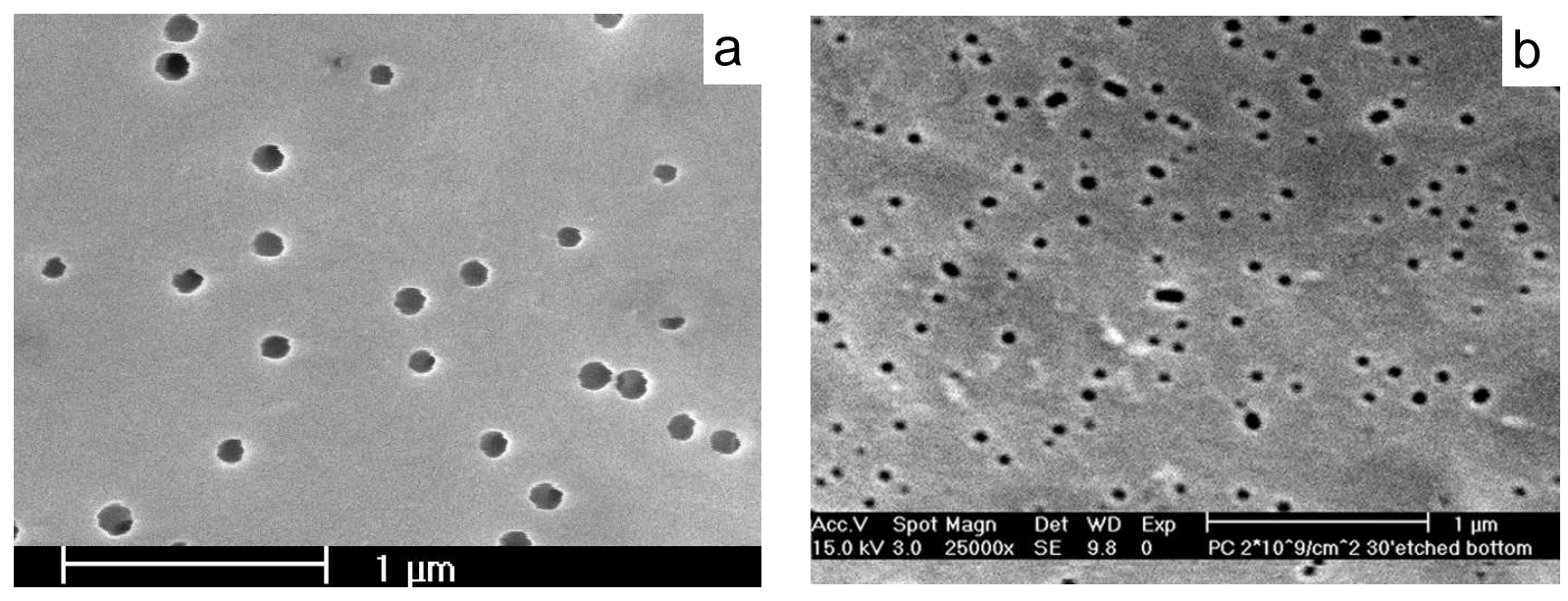

Figure $4 a$ and $b$ 



Figure $5 \mathrm{a}$ and $\mathrm{b}$ 

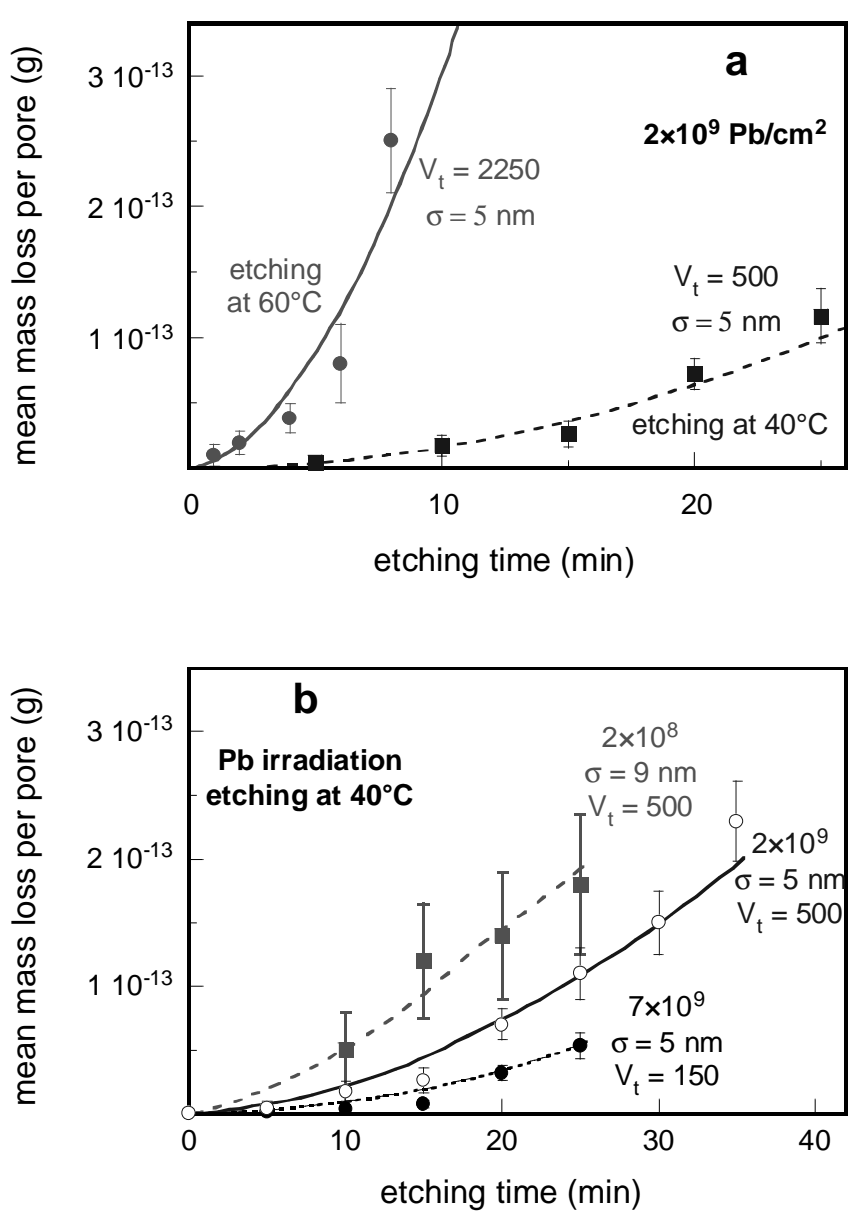

Figure $6 a$ and $b$ 